\title{
Managing Diversity In The Midst Of Homogeneity: Lessons Learned In Rural Service Learning
}

Nicholas Holton, Kirtland Community College, USA

\begin{abstract}
Rural areas are known for their homogeneity. Although cultures in different rural areas are often distinct and even unique, the culture within a given rural area is often easily characterized by one skin color, one language, one set of morays, and one mindset toward governmental institutions. Service Learning combines real academic learning in a community service setting. Are some diversity issues pandemic across rural areas? How do these issues impact Service Learning programs in rural areas and how can even remote places like Alaska benefit from the lessons learned?
\end{abstract}

\section{A PRIMER ON SERVICE LEARNING}

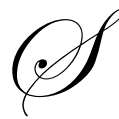

ervice Learning is a pedagogical model that connects meaningful community service experiences with academic course learning. This is not something that faculty add on to courses. Instead, Service Learning is an intentional use of community service placements of students to teach course content.

The community benefits from Service Learning because it provides human resources to meet educational, human, safety and environmental needs of communities. It allows the enthusiasm and energy of students to contribute to meeting local needs. The community also develops a much healthier relationship with the college or university. The "town/gown" love-hate relationship is improved when students are visibly engaged in area improvement.

Students in Service Learning programs benefit from real world experience in relevant settings. This is invaluable as they prepare to compete in a tough job market. As one of my students once commented, "It provides valuable experience and if you screw up, you can't get fired!" At first blush, this comical statement is more real than we may think. Perhaps she did get fired from some position. The Service Learning opportunity has provided her with a successful experience and might be the positive start of a bright future.

The university will benefit from improved relationships in the community. Universities strive to be engaged citizens in their communities and now, through Service Learning, students can achieve curricular objectives while solving their community's problems.

The essential elements for Service Learning programs and projects are Reciprocity, Reflection, Development, Meaningful Service, and Diversity. Projects must be beneficial to both the college and the community partner. Shared planning, decision-making, budgeting and assessment assure mutual gain and sustainability for all.

Meaningful service only enhances student development if there are sufficient opportunities for reflection. It's through reflection that the community service experience is internalized, the curricular objectives are stored in long-term memory and the student gains an appreciation for the power of community service to make change. This metacognitive process is crucial for the student to understand the impact the service has on the community and on the life of the student. 
Diversity is an important factor in Service Learning as well. This doesn't have to mean diversity in terms of cultures or ethnic backgrounds, although it could. Rather, the diversity in rural areas refers to economic diversity between the haves and have-nots; the geographic diversity between those with technology, health care, etc. and those without; and finally, it could mean the diversity of opinion between the concepts of service versus the "I'm in it for me" mentality. Well-designed programs address all of these.

\section{RURAL SERVICE LEARNING CHALLENGES OR OPPORTUNITIES}

Large urban centers point with pride to large and impressive Service Learning programs that address critical community problems. However, these same problems exist in rural areas, but are just proportionally less prevalent. Yet, rural areas face a number of challenges that, left unaddressed, could derail the best-planned community partnerships.

Large geographical areas surrounding rural districts create logistical problems with transportation and finding opportunities close to home. To be successful, Service Learning practitioners adjust their attitude and their concept of neighborhood from the micro of the subdivision to the macro of the whole county or parish. Unfortunately, often the size of the rural college is inversely proportional to the geographical size of the district. Yet, a smaller college can implement a viable sustainable Service Learning program easier because of the smaller bureaucracy. Curricular changes are implemented easier, approvals come quicker and there are less faculty per department to convince. So, smaller rural colleges have the chance to experiment, implement and assess projects quickly.

The small population density of rural areas leads to a dearth of community agency infrastructure. This causes difficultly in creating strong community partnerships. Subsequently, faculty can be reluctant to participate, experiment, and innovate. The small number of faculty will lack networking possibilities and no support net for Service Learning novitiates. Thus, it is crucial for the college or university to support Service Learning through resources, rewards, recognition, and special events.

\section{LESSONS LEARNED IN RURAL SERVICE LEARNING}

What are the lessons learned from rural Service Learning programs that can help the institutional management of diversity?

Rethink the obvious. If an essential element of Service Learning is diversity and the rural community is homogenous, where's the diversity? How does one attempt to manage this? What are the implications for others? As mentioned above, diversity could mean diverse economic realities for an ethnic homogenous community. My college district in the northern lower peninsula of Michigan is a predominately white area. There are few African Americans, Hispanics or Asian Americans. There is a tribal presence, but this is mostly surrounding tribal lands where the resulting casinos seem to multiply every year. However, there is a serious economic divide in the region. There are a small minority of residents that are in the middle and upper class. The vast majority is economically disadvantaged with per capita income far below the national average and the unemployment rate far above the national average. Trying to bring these two groups together is a constant struggle. Also, getting the reluctant disenfranchised economically depressed student to realize that they can and should contribute to their community in a meaningful way is always a challenge. Yet, the sense of empowerment for these students is worth all the work. Inevitably, these are the students who change their majors to more socially conscience choices that will prepare them for a life of giving back to their hometown. Organizational administrators charged with implementing diversity often are stuck in the old mindsets left over from the last decade. Take some time to step back and look at the situation from a different angle. Recognize that diversity can take on many forms. Get someone from outside of the organization or outside of the field to provide observations on ways to encourage diversity.

Even small efforts make a difference. Often we think that our efforts are too little too late to make a difference. Rural Service Learning programs refute this. At my rural college a nature study class collected litter as they learned about the unique flora and fauna in a conservancy area. The instructor complained about the amount of litter coming from a nearby factory. One of the students with a family connection to the factory convinced the owner to fence the 
dumpsters to prevent the wind from dispersing the trash. The point is that one person in one place doing one thing can lead to change. From Rosa Parks, to Gandhi we see, again and again, that the great movements of thousands of people are sparked from the actions of a few. Convincing our students that this is possible is the first step to creating an engaged student body. For those interested in diversifying their workplace, small steps can be the most productive. Rather than a massive program for promoting diversity, small policy and procedural changes can effect great change in small increments that add to major changes over time.

Managing diversity is more than facilitating change. Rural Service Learning programs show that real change can be accomplished and attitudes can change with an economically and educationally diverse but ethnically homogeneous population. This analogy can be transferred to other situations. Diversity managers must be diligent to embrace new methods and tactics that enhance the strengths of a diverse workplace, even when the demographics show little ethnic variety. Creative professional development, positive networking opportunities and real institutional support are just as important as the efforts of the diversity manager. There must be a real commitment on the part of the organization for this to succeed. These resources create an environment that welcomes diversity, nurtures new cultures in the workplace, and builds strong bonds between culturally different people.

Initial resistance can lead to acceptance. Many of my students are unwilling to do Service Learning projects. They cite many reasons, but frequently their reflection papers indicate an extreme reluctance for community service and they see little reason for the assignment. Invariably however, those that follow the assignment and actively participate in the project will then write about how their attitude has changed completely. The power of the pedagogy has now convinced them that performing community service not only has the potential to teach them something, but also has the power to change things for the better. Organizations meet a similar resistance in diversification issues. However, as the workplace becomes more diverse, most will see the benefits to the organization. Sure, there will be growing pains and developing policies and procedures that adequately address the new diversity paradigm can and will cause angst, but the benefits outweigh the costs.

\section{FINAL THOUGHTS}

Managing diversity in the post affirmative action era often creates issues requiring attention. Managers must develop strategies that:

- $\quad$ Communicate the need to change

- $\quad$ Develop growth in target ethnic, gender, and socio-economic groups

- $\quad$ Nurture acceptance

These strategies have the potential to be national models of diversity, easily replicable around the county. By applying the lessons learned in other proactive initiatives like Service Learning, managers can discover new techniques for training, communication and implementation. Overcoming resistance through incremental changes that rethink the basic tenets of diversity management generates more than a changing look to an organization. It renews the spirit of innovation and produces a workforce tolerant of others that embraces the best of all of us. 
NOTES 